\title{
Ecological Factors Influencing Severity of Cashew Fusarium Wilt Disease in Tanzania
}

*Corresponding author

Tel: $+255-743432887$

E-mail: stanliliac@gmail.com

ORCID

https://orcid.org/0000-0002-0160-950X

\author{
Stanslaus A. Lilai ${ }^{1}{ }^{2 *}{ }^{D}$, Fortunus A. Kapinga ${ }^{1}$, Wilson A. Nene ${ }^{1}$, William V. Mbasa, ${ }^{1,2}$ \\ and Donatha D. Tibuhwa ${ }^{2}$ \\ ${ }^{1}$ Tanzania Agriculture Research Institute, Naliendele, P.O. Box 509, Mtwara 63115, Tanzania \\ ${ }^{2}$ Department of Molecular Biology and Biotechnology, College of Natural and Applied Sciences, \\ University of Dar es Salaam, Dar es Salaam 022, Tanzania
}

Received February 11, 2021

Revised May 13, 2021

Accepted June 25, 2021

\begin{abstract}
Cashew (Anacardium occidentale L.) is an important cash crop in Tanzania as a source of income to cashew growers and provides foreign exchange for the country. Despite its significance, the crop is threatened by fast spreading disease known as cashew Fusarium wilt caused by Fusarium oxysporum. Field assessment and laboratory tests were conducted to determine incidences of the disease, severity, ecological factors that influence them and explored the pathogen host specificity in six cashew growing districts. The results revealed significant $(P<0.001)$ variation of disease incidences and severity among the studied districts. The results further revealed that there is both positive and negative correlation between the incidence and severity of the disease versus the evaluated ecological factors. The soil pH, soil temperature, air temperature, and relative humidity depicted positive correlation of disease incidence and severity versus ecological factors at $\rho=0.50$ and $\rho=0.60, \rho=0.20$ and $\rho=0.94, \rho=0.11$ and $\rho=0.812, \rho=0.05$ and $\rho=0.771$ respectively while nitrogen, phosphorus, and carbon depicted negative correlations at $\rho=-0.22$ and $\rho=-0.58, \rho=-0.15$ and $\rho=-0.94$, $\rho=-0.19$ and $\rho=-0.12$ respectively. In terms of host range, none of the weed species was found to be a carrier of Fusarium pathogen implying that it is host specific or semi selective. The results revealed that the tested ecological parameters favor the growth and development of Fusarium pathogen. Thus, management of the disease requires nutrients replenishment and soil shading as essential components in developing appropriate strategies for the control and prevention of further spread of the disease.
\end{abstract}

Keywords: Cashew, Ecological factors, Fusarium oxysporum, Host range

\section{Introduction}

Cashew (Anacardium occidentale L.) is one of the main commercial crops grown in Tanzania. It is the source of income to most cashew growing communities in Tanzania (Madeni, 2016) and provides foreign exchange in the country. According to the Bank of Tanzania Annual report of 2017/2018, cashew production has been significantly increasing for over

Research in Plant Disease

pISSN 1598-2262, elSSN 2233-9191

www.online-rpd.org six consecutive years from the year $2011 / 2012$ to $2017 / 2018$. For example, during the cashew season of 2011/2012, the country's earnings were $174,240,000$ million Tanzanian shillings whereas in 2017/2018, the country earned about 1.3 trillion Tanzanian shillings (565,168,240 USD).

The processed cashew kernels give cashew milk and butter as the source of proteins and fats (Rico et al., 2015). Cashew apple can be processed into cashew apple juice and wine, which contain vitamin $\mathrm{C}$, iron ( $\mathrm{Fe})$, and zinc $(\mathrm{Zn})$, which are essential for human health (Msoka et al., 2017). The edibility property of raw cashew apple and nut kernel in either raw or roasted form makes cashew more advantageous than other 
food crops (Rico et al., 2015).

Despite the importance of cashew crop in Tanzania, its production has been constrained by several factors including attacks by insect pests, and diseases that include fungal related ones (Dominic and Makobe, 2016; Nene et al., 2017; Sijaona et al., 2006).

In 2012, a new disease which caused deaths of cashew trees emerged in cashew fields at Magawa village $\left(07^{\circ} 27^{\prime} 55.5^{\prime \prime} \mathrm{S}, 039^{\circ} 14^{\prime} 51.6^{\prime \prime} \mathrm{E} ; 43 \mathrm{~m}\right.$ above sea level) in Mkuranga, Coast region of Tanzania. The infestation led to the loss of hundreds of hectares of cashew trees, leaving small scale farmers with increased poverty and led to the loss of a country income through reduced or lower earning of foreign currency (Tibuhwa and Shomari, 2016). However, the causative agent, the extent and magnitude of the infestation and the factors influencing the severity of the disease were heretofore not yet studied.

Therefore in 2016, a field assessment was conducted at Magawa village cashew fields where field observations and sampling were conducted to identify the pathogen, F. oxysporum (Tibuhwa and Shomari, 2016).

F. oxysporum is a soil-borne ascomycete and anamorphic species, which causes deadly vascular wilting syndrome in several plants (Matić et al., 2018). It reproduces asexually and can remain dormant in the soil by means of chlamydospores (Pérez-Vicente et al., 2014). The pathogen produces spores, which are found either out or in the plant tissues. The pathogen can also exist in both macro and microconidia (JiménezDiaz et al., 2015).

Several studies in other crops indicate the association between the severity of Fusarium wilt disease with both biotic and abiotic factors (Devika et al., 2017; Orr and Nelson, 2018; Rousk et al., 2010). For example, it was established that development and virulence of Fusarium pathogen correlates with edaphic factors particularly soil nutrients (Pérez-Vicente et al., 2014), temperature (Peng et al.,1999), relative humidity (Gheorghe et al., 2015), and soil pH (Tibuhwa and Shomari, 2016). Another study (Peng et al., 1999) on Fusarium wilt disease attacking banana and lettuce indicated that, an increase of temperature between $24-34^{\circ} \mathrm{C}$ and $26-28^{\circ} \mathrm{C}$ led to an increase of disease severity. The presence of mineral elements in optimal amount in soils suppresses the pathogenicity of $F$. oxysporum. High phosphorus content in the soil reduces incidences of Fusarium wilt. Similar observations on the influence of mineral nitrogen and organic carbon in the suppression of Fusarium wilt disease was reported in banana crop (Orr and Nelson, 2018; Perez-Vicente et al., 2014). High relative humidity favours pathogen sporulation and infectivity (Gheorghe et al., 2015). Study of edaphic factors can help to identify the status of soils in cashew fields affected by Fusarium wilt disease and suggest for soil amendment requirements for the control of the disease.

Fusarium wilt disease is reported in both crops and noncrops (Pérez-Vicente et al., 2014). Pathogenic isolates of F. oxysporum have high degree of host specificity (AlvesSantos et al., 1999). Based on the species and host cultivar attacked, the isolates of $F$. oxysporum are further divided into formae speciales and races, respectively (Alves-Santos et al., 1999). However, studies have reported that, the same formae speciales can be isolated on a wide range of plants including alternative and weed hosts, either as pathogenic or carrier (Matić et al., 2018; Pérez-Vicente et al., 2014). Thus, in this study the host range was also assessed particularly on weeds surrounding the affected cashew trees.

Since its first outbreak at Magawa, similar symptoms of the disease were further reported to have attacked hundreds of cashew trees in different cashew fields in the south east of Tanzania, which was later confirmed to be Fusarium wilt in cashew. For example two cashew fields out of five in south of Liwale district (Lindi region) had similar symptoms in which first and second cashew fields had 10 and 3 out of 22 and 13 cashew trees affected by the disease respectively and at Nachingwea district, three cashew fields out of nine were assessed and only three cashew trees were affected in a cashew field with a total of 31 cashew trees (report by District Agriculture and Irrigation Cooperative offices).

Therefore, following report from the previous field assessment, it was hypothesized that, there would be more incidences of the disease in cashew producing regions particularly cashew fields bordered by already affected cashew fields. Thus, in this study, further surveys were conducted in order to get reliable estimate in terms of disease incidences, severity and its influencing ecological factors. These can be used as the basis for making right decisions in developing appropriate strategies for controlling the disease (Amata et al., 2009; Campbell and Neher, 2016; Molina et al., 2010; Pérez-Vicente et al., 2014). 


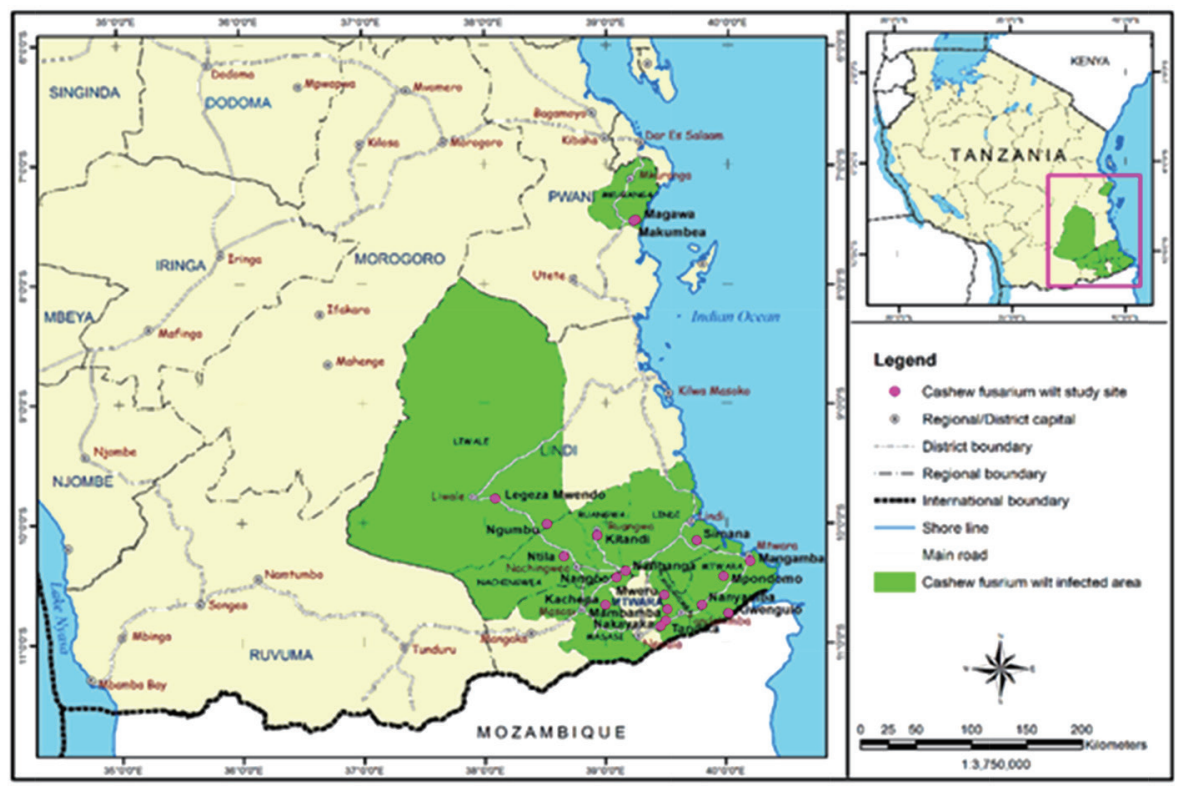

Fig. 1. Map showing areas infected by Fusarium wilt of cashew in the Coast, Lindi, and Mtwara regions in Tanzania (drawn by Laurence Emmanuel).

\section{Materials and Methods}

Description of the study area. Field assessments were conducted in 2012, 2016 and 2019. However, the data collected in 2012 and 2016 were from single site (Magawa village) as a result were not informative. Therefore intensive field assessments were conducted at the end of a rainy season (April to May 2019) in six districts within three cashew growing regions.

Lindi which lies between latitudes $10^{\circ} \mathrm{S}$ and $11^{\circ} \mathrm{S}$ and between longitudes $37^{\circ} \mathrm{E}$ and $40^{\circ} \mathrm{E}$ and Mtwara which lies between latitudes $7^{\circ} \mathrm{S}$ and $10^{\circ} \mathrm{S}$ and between longitudes $36^{\circ} \mathrm{E}$ and $39^{\circ} \mathrm{E}$ are found about $500 \mathrm{~km}$ from Coast region where the first case of cashew wilt disease was reported. A total of six districts were involved namely; Newala, Masasi, and Tandahimba-Mtwara Region, Liwale and Nachingwea — Lindi Region and Mkuranga in Coast region (Fig. 1). Coast region is located along the coastal belt of Indian Ocean, South East of Dar es Salaam (one of the important cities in Tanzania).

The rainfall trend of the regions is characterized by a unimodal pattern commencing from late November and lasting until late April and the annual rainfall ranges from 810 to 1,090 $\mathrm{mm}$. The mean maximum and minimum temperatures are $29^{\circ} \mathrm{C}$ and $24^{\circ} \mathrm{C}$, respectively (Nene et al., 2017).

Sampling to determine incidence and severity of Fusarium wilt in cashew. The districts were selected by purposive sampling based on the agro-ecological zones and their production potential but also following reported cases of $\mathrm{Fu}$ sarium wilt in cashew from District Agriculture and Irrigation Cooperative offices. A total of 12 cashew fields were assessed (Fig. 1). These included; Makumbea in Mkuranga districtCoast region, Nanganga in Masasi, Nakayaka in Tandahimba and Kitangali in Newala district in Mtwara region and Ntila, Nditi A, Nditi B, and Kipara Mnero in Nachingwea district, and Tuungane A, Tuungane B, Majimaji, and Legeza Mwendo in Liwale district in Lindi region. The infected cashew trees were identified by visual observation on leaf symptoms (Fig. 2) followed by laboratory tests at the University of Dar es Salaam to confirm the causative agent.

Single spore isolation and morphological identification of F. oxysporum. The pathogen, F. oxysporum was isolated aseptically by plate-tube culture technique whereby, plant material (10 mm root sections) were sterilized prior to culturing using $1 \%$ sodium hypochlorite $(\mathrm{NaClO})$ in $1 \mathrm{~min}$ as well $70 \%$ alcohol for bench sterilization. A single spore (conidia) was isolated from sporulating hyphae on potato dextrose agar (PDA) culture plate by collecting a fungal scrape which was dissolved in $10 \mathrm{ml}$ of sterile distilled water in test tubes. This was followed by 10 -fold serial dilutions. One $\mathrm{ml}$ of each dilution was pipetted and streaked on PDA culture plates. 

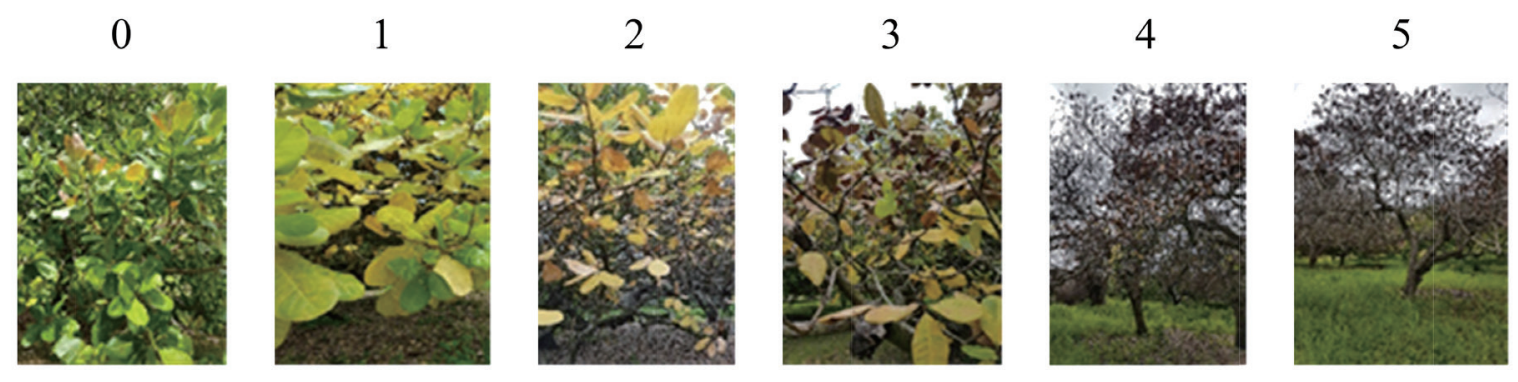

Fig. 2. Pictorial representation of leaf symptoms of Fusarium wilt disease scale, rated 0 -5 (green leaves, chlorotic, yellow leaves, brown+some yellow leaves, brown leaves+wilted shoots and wilted plant, respectively).

The plates were incubated at $28^{\circ} \mathrm{C}$ for four days and closely observed under dissecting microscope to localize the growing conidia which was then transferred using sterile scalpel to a new $90 \mathrm{~mm}$ plates containing PDA. Isolation of the pathogen followed the protocol prepared by Pérez-Vicente et al. (2014) with little modification. Bacterial contamination was prevented using antibiotic (streptomycin) at $1.5 \mathrm{ml} / 300$ $\mathrm{ml}$ of PDA. Identification of the $F$. oxysporum followed the same procedures as adapted by Tibuhwa and Shomari (2016) and Mbasa et al. (2020) whereby macro-micromorphology were carefully studied, the observed macro characteristics included white cotton-like, salmon to pale violate margin with age turns to fuss form, reverse slightly dark and micro characteristics were oval spores (conidia) i.e., macro-conidia, micro-conidia and chlamydospores which were studied using compound light microscope (Olympus cx41, Tokyo, Japan) at $\times 40$ magnification.

\section{Determination of incidence and severity of Fusarium wilt in} cashew. Incidences were determined by counting all the infected trees divided by the total number of trees times 100 (Amata et al., 2009; Patra et al., 2017). The formula for disease incidence is shown below;

$$
\text { Disease incidence }(\%)=\frac{\text { No of infected plants }}{\text { No of observed plants }} \times 100
$$

Disease severity was determined using leaf symptom expression scale 0 to 5 . Zero (0) stands for no infection and 5 stands for the infection of the whole cashew canopy or branches as adapted from (Lichtenzveig et al., 2006; Lima et al., 2019; Molina et al., 2010) with some modification (Fig. 2). The formula for disease severity is shown below.

$\begin{gathered}\text { Disease } \\ \text { severity }(\%)=\end{gathered} \times 100$

, where; $0(0 \%)=$ green leaves, $1(1-20 \%)=$ chlorotic, 2 $(21-40 \%)=y e l l o w$ leaves, $3(41-60 \%)=$ brown leaves+some yellow leaves, $4(61-80 \%)=$ brown leaves+wilted shoots, 5 (81-100\%)=wilted plant/cashew.

Four acres (120 cashew trees) per field were covered for disease incidences and severity.

Ecological factors associated with Fusarium wilt of cashew. Prior to soil sampling, the study areas (cashew fields) were examined for soil type homogeneity which was observed to be similar (sand-loamy). Both field and laboratory works were performed for determination of ecological factors. A total of five soil samples from each study area, which were collected from five symptomatic plant rhizosphere niches sampled randomly, were mixed (composite) to form two samples per field at the depth ranging from 0 to 20 $\mathrm{cm}$ and 20 to $50 \mathrm{~cm}$. The samples were sent to the Botany Laboratory of the University of Dar es Salaam for analysis. Soil parameters $(\mathrm{pH}$, electrical conductivity, soil mineral nutrients, and soil temperature) and other abiotic factors (relative humidity) were determined. Relative humidity and soil temperature were determined in the cashew fields using wet, dry bulb thermometer, and soil thermometer at $20 \mathrm{~cm}$ depth respectively. Soil $\mathrm{pH}$ and electrical conductivity were determined using $\mathrm{pH}$ meter (Fisher Scientific AB 15, Thermo Fisher Scientific, Pittsburgh, PA, USA) and electrical conductivity meter (Jenway 4510, Bibby Scientific (Cole-Parmer), Chelmsford Essex, UK), respectively. 
Soil mineral nutrients analysis. Three soil mineral nutrients were determined. Nitrogen and the available phosphorus were determined calorimetrically using spectrophotometer (Jenway 6305, Bibby Scientific (Cole-Parmer)) whereas organic carbon was determined titrimetrically. IndophenolBlue method (Rowland, 1983), determination of orthophosphate based on the reduction of antimony (III) with ascorbic acid and Walkley-Black method (Walkley, 1947) were used to determine the total nitrogen, available phosphorus, and organic carbon, respectively. Soil mineral nutrients and salinity levels (critical and normal) were classified according to Food and Agriculture Organization standards in which mineral nitrogen levels of $<0.10,0.10-0.20,0.21-0.51$, and $>0.51$ are classified as trace, low, medium and high respectively, organic carbon ( $<0.60,0.60-1.25,1.26-2.50$, and 2.51-3.50), available $P$ by Bray I method $(0,<7 \mathrm{mg} / \mathrm{kg}, 7-20 \mathrm{mg} / \mathrm{kg}$, and $>20 \mathrm{mg} / \mathrm{kg})$ and salinity $(<4 \mathrm{mS} / \mathrm{cm}, 0,9-15 \mathrm{mS} / \mathrm{cm}$, and $>15$ $\mathrm{mS} / \mathrm{cm}$ ) respectively (Food and Agricultuer Organization of the United Nations, 1982, 2015).

Determination of Host range of $F$. oxysporum in the infected cashew fields. Using a line transect procedure, a $100 \mathrm{~m}$ tape measure was laid down from the stem of symptomatic cashew trees to the edge of canopies (distance from the stem to the cashew canopy was about 6 meter). Dominant weeds ( $2-3$ weeds per tree) in close proximity to the infected cashew tree were sampled as per compass direction $(\mathrm{N}, \mathrm{S}$, and $W, E)$. Sampling of the common weeds were conducted using square meter $(1 \mathrm{~m} \times 1 \mathrm{~m})$ quadrat lied within the line transect (distance covered by tape measure) and most fre-

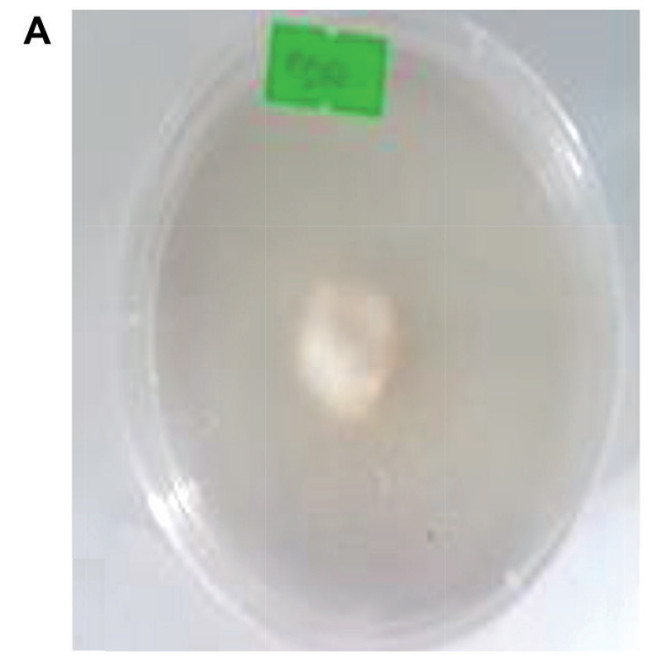

quent weeds were sampled.

The samples were sent to the Botany Department at the University of Dar es Salaam for botanical identification (Herbarium) and laboratory analysis in which isolation and identification of the F. oxysporum from weeds (roots) was conducted under aseptic environment, root samples (5-10 $\mathrm{mm}$ long sections) were sterilized prior to culturing using $1 \%$ sodium hypochlorite ( $\mathrm{NaClO}$ ) in $1 \mathrm{~min}$ as well $70 \%$ alcohol for bench sterilization. PDA was used for culturing of prepared root samples, which were left four days at $28^{\circ} \mathrm{C}$ for incubation. The isolation of the pathogen followed the protocol prepared by (Pérez-Vicente et al., 2014) whereby bacterial contamination was prevented using, $1 \mathrm{ml}$ streptomycin per volume of PDA.

Data analysis. A Kruskal-Wallis one-way analysis of variance was performed to test significance (disease incidence and severity) among the surveyed areas while a Mann-Whitney $U$ test was performed to compare the disease incidence and severity between regions and districts.

Spearman correlation was performed to assess the correlation between ecological factors (soil pH, mineral nutrients, relative humidity, and soil and air temperatures) versus disease incidence and severity. All data were analyzed using GenStat Discovery Software version 15.1 release PL 23.1.

\section{Results}

Isolation and morphological identification of $F$. oxysporum. The root sections were grown on PDA for 4 days at

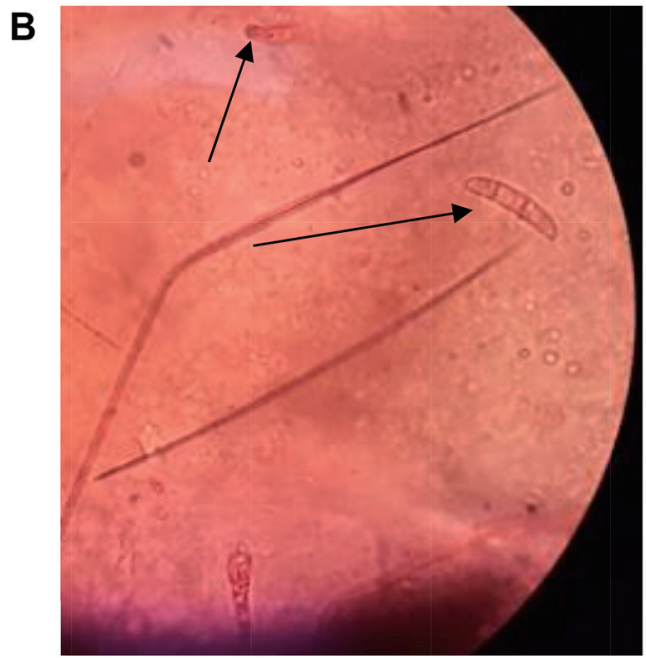

Fig. 3. Culture (A) and microscopic (B) identification of Fusarium oxysporum. 
Table 1. Kruskal-Wallis test for Fusarium wilt disease incidence and severity across the regions and districts

\begin{tabular}{|c|c|c|c|c|c|c|c|}
\hline \multirow{2}{*}{\multicolumn{2}{|c|}{ Infected areas }} & \multicolumn{3}{|c|}{ Disease incidence } & \multicolumn{3}{|c|}{ Disease severity } \\
\hline & & \multirow{2}{*}{$\frac{\text { Mean rank }}{20.5}$} & \multirow{2}{*}{$\frac{\text { H-value }}{20.48}$} & \multirow{2}{*}{$\frac{P \text {-value }}{<0.001}$} & \multirow{2}{*}{$\frac{\text { Mean rank }}{20.5}$} & \multirow{2}{*}{$\frac{\text { H-value }}{20.48}$} & \multirow{2}{*}{$\begin{array}{c}\text { P-value } \\
<0.001\end{array}$} \\
\hline Regions & Lindi & & & & & & \\
\hline & Mtwara & 12.5 & & & 12.5 & & \\
\hline & Coast & 4.5 & & & 4.5 & & \\
\hline \multirow[t]{6}{*}{ Districts } & Newala & 7.8 & 24.12 & $<0.001$ & 9.7 & 20.75 & $<0.001$ \\
\hline & Tandahimba & 9.6 & & & 11.7 & & \\
\hline & Masasi & 6.9 & & & 13.4 & & \\
\hline & Mkuranga & 17.7 & & & 7.2 & & \\
\hline & Liwale & 26.2 & & & 25.8 & & \\
\hline & Nachingwea & 24.8 & & & 25.2 & & \\
\hline
\end{tabular}

$P<0.001$ : highly significant different.

$28^{\circ} \mathrm{C}$ and three fungal isolates were observed (Aspergillus spp., Trichoderma spp., and Fusarium spp.) however, only Fusarium isolate was used for morphological identification. The culture growth and microscopic features were evident of $F$. oxysporum. Cottony like growth with whitish colour at young stage (3-day-old culture) with age it turned pale violate to pinkish. Microscopically, oval to kidney shaped spores were prominent ranging from micro to macro-conidia, the macroconidia spores have 3 to 5 septa hyphae while micro have one septum (Fig. 3).
Incidence and severity of Fusarium wilts of cashew. A total of six districts were surveyed in three regions and 1,294 cashew trees were involved in the experiment. Table 1 presents mean ranks of disease incidence and severity among the studied regions and districts. The present study showed significant variation of disease incidence and severity between studied districts $(P<0.001)$. Liwale district recorded the highest mean percentage of disease incidence (35.6\%) followed by Nachingwea (30.8\%), Mkuranga (13\%), Tandahimba $(9.8 \%)$, Newala (9.4\%) and the lowest was recorded in Ma-

Table 2. Status of ecological factors across the districts

\begin{tabular}{|c|c|c|c|c|c|c|c|c|c|}
\hline Districts & SD & pH & EC & $\mathbf{N}$ & $\mathbf{P}$ & C & ST & AT & RH \\
\hline \multirow[t]{2}{*}{ Mkuranga } & $0-20$ & 5.6 & 7.81 & 0.09 & 0.10 & 2.63 & \multirow[t]{2}{*}{35.6} & \multirow[t]{2}{*}{31.4} & \multirow[t]{2}{*}{75} \\
\hline & $20-50$ & 5.5 & 2.51 & 0.07 & 0.01 & 0.81 & & & \\
\hline \multirow[t]{2}{*}{ Liwale } & $0-20$ & 5.0 & 6.3 & 0.06 & 0.03 & 2.58 & \multirow[t]{2}{*}{32.6} & \multirow[t]{2}{*}{28.6} & \multirow[t]{2}{*}{70} \\
\hline & $20-50$ & 6.1 & 4.71 & 0.10 & 0.01 & 3.25 & & & \\
\hline \multirow[t]{2}{*}{ Tandahimba } & $0-20$ & 5.3 & 3.87 & 0.10 & 0.02 & 1.92 & \multirow{2}{*}{28.4} & \multirow{2}{*}{26.6} & \multirow{2}{*}{59} \\
\hline & $20-50$ & 4.8 & 4.14 & 0.07 & 0.01 & 1.52 & & & \\
\hline \multirow[t]{2}{*}{ Masasi } & $0-20$ & 6.5 & 16.53 & 0.07 & 0.13 & 3.99 & \multirow{2}{*}{31.1} & \multirow{2}{*}{30.2} & \multirow{2}{*}{77} \\
\hline & $20-50$ & 6.7 & 12.24 & 0.10 & 0.02 & 3.74 & & & \\
\hline \multirow[t]{2}{*}{ Newala } & $0-20$ & 5.9 & 4.64 & 0.08 & 0.05 & 2.02 & \multirow{2}{*}{30.2} & \multirow{2}{*}{28.4} & \multirow{2}{*}{62} \\
\hline & $20-50$ & 5.8 & 3.48 & 0.07 & 0.03 & 3.28 & & & \\
\hline \multirow[t]{2}{*}{ Nachingwea } & $0-20$ & 5.3 & 3.43 & 0.08 & 0.15 & 4.99 & \multirow{2}{*}{30.6} & \multirow{2}{*}{28.8} & \multirow{2}{*}{65} \\
\hline & $20-50$ & 5.1 & 4.23 & 0.20 & 0.14 & 3.94 & & & \\
\hline
\end{tabular}

$\mathrm{SD}$, soil depth (cm); $\mathrm{pH}$, soil $\mathrm{pH}$; $\mathrm{EC}$, electrical conductivity $(\mu \mathrm{S} / \mathrm{cm}) ; \mathrm{N}$, nitrogen (\%); $\mathrm{P}$, phosphorus in $\mathrm{mg} / 100 \mathrm{~g}$ of soil; $\mathrm{C}$, organic carbon

(\%); $\mathrm{ST}$, soil temperature $\left({ }^{\circ} \mathrm{C}\right) ; \mathrm{AT}$, air temperature $\left({ }^{\circ} \mathrm{C}\right) ; \mathrm{RH}$, relative humidity $(\%)$. 

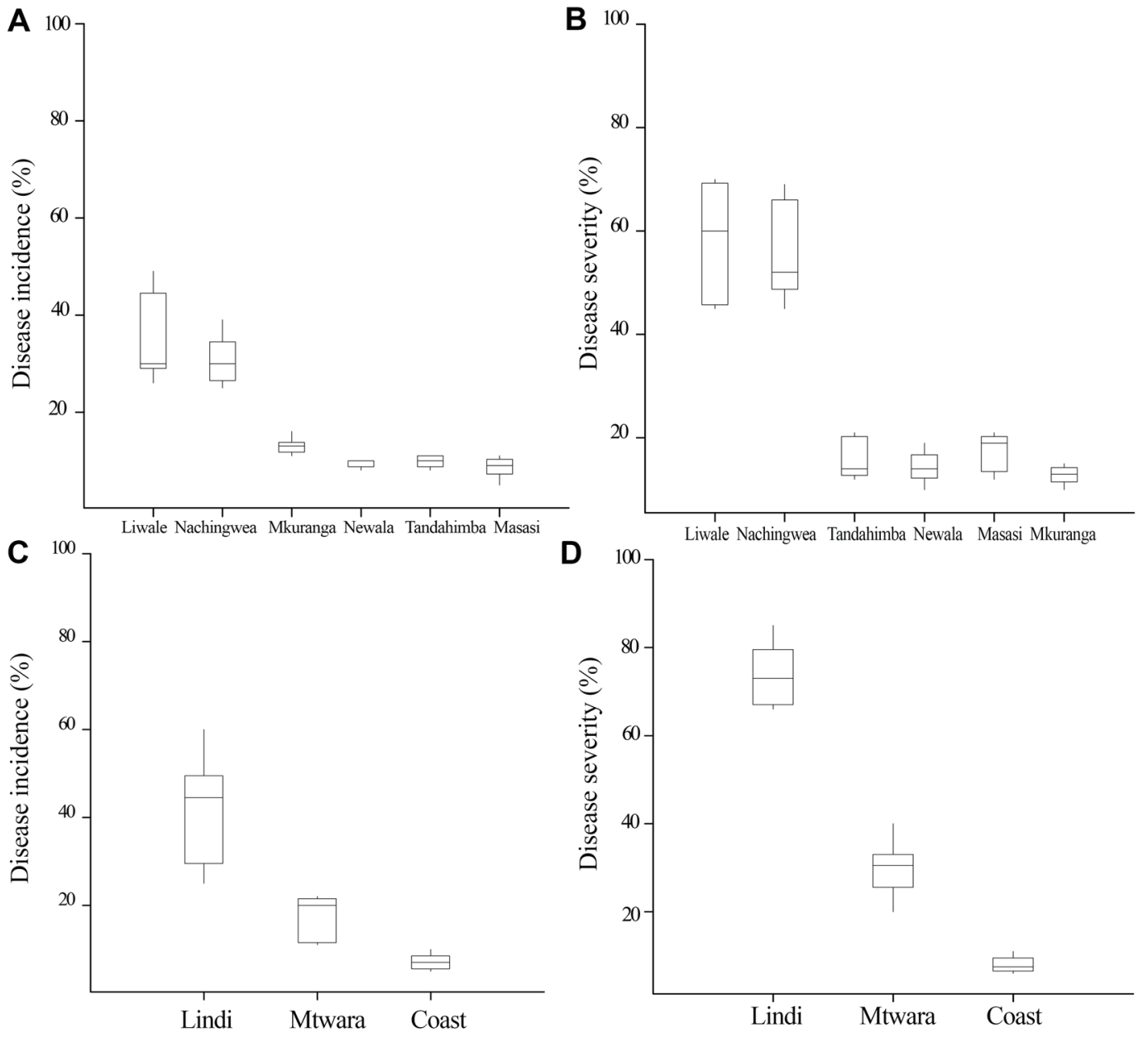

Fig. 4. Box plots showing disease incidence (A) and disease severity (B) of Fusarium wilt of cashew in six districts of Coast, Lindi and Mtwara regions. Box plots showing disease incidence $(C)$ and severity $(D)$ of Fusarium wilt of cashew in Coast, Lindi, and Mtwara regions.

sasi district (8.6\%) (Fig. 4A). The study findings also showed that the mean percentages of disease severity varied among districts with the maximum of $58 \%$ in Liwale, followed by Nachingwea (56.2\%), Masasi (17.2\%), Tandahimba (16\%), Newala (14.4\%) and the lowest was recorded in Mkuranga district (12.8\%) (Fig. 4B). Fusarium wilt disease was observed to be more severe in Liwale (mean percent, 58) district than in all other districts except Nachingwea (56.2\%) which was as high as Liwale. There was significance difference in the disease incidence and severity across the regions $(P<0.001)$ (Table 1). Lindi region recorded the highest disease incidence and severity percentages (mean, $41.5 \%$ and $71.4 \%$ ) followed by Mtwara (17.4\% and $30 \%)$ and Coast $(7.1 \%$ and $8 \%)$, respectively (Fig. 4C, D).

\section{Correlation of ecological factors and Fusarium wilt disease}

of cashew. The present study showed the correlation of ecological factors with both incidence and severity of Fusarium wilt disease. Table 2 presents the status of ecological factors across the districts. Correlations analysis revealed both positive and negative correlations between disease incidence/severity and ecological factors among the studied locations (Tables 3, 4). Positive correlations for disease incidence and severity were found between soil $\mathrm{pH}$, soil temperature, air temperature, and relative humidity depicted by low and high correlation coefficients of $\rho=0.50$ and $\rho=0.60, \rho=0.20$ and $\rho=0.94, \rho=0.11$ and $\rho=0.812, \rho=0.05$ and $\rho=0.771$ while negative correlations were observed between nitrogen, phosphorus, and carbon with $\rho=-0.22$ and $\rho=-$ $0.58, \rho=-0.15$ and $\rho=-0.94, \rho=-0.19$ and $\rho=-0.12$ respec tively. For example, soil $\mathrm{pH}$ values across the study districts ranged from 5.0 to 6.5 at the $0-20 \mathrm{~cm}$ depth and from 4.8 to 
Table 3. Spearman correlation matrix between ecological factors and disease incidence

\begin{tabular}{lccccccccc}
\hline & DI & pH & EC & N & P & C & ST & AT & RH \\
\hline DI & 1.000 & & & & & & & & \\
pH & 0.496 & 1.000 & & & & & & & \\
EC & 0.241 & 0.291 & 1.000 & & & & & & \\
N & -0.228 & -0.219 & -0.450 & 1.000 & & & & & \\
P & -0.148 & 0.105 & 0.214 & 0.113 & 1.000 & & & & \\
C & -0.185 & -0.126 & 0.243 & -0.318 & 0.669 & 1.000 & & & \\
ST & 0.160 & 0.042 & 0.559 & -0.311 & -0.021 & 0.176 & 1.000 & & \\
AT & 0.111 & 0.145 & 0.545 & 0.085 & 0.664 & 0.610 & 0.596 & 1.000 \\
RH & 0.053 & 0.325 & 0.909 & -0.393 & 0.350 & 0.461 & 0.699 & 0.761 & 1.000 \\
\hline
\end{tabular}

If $\rho$ value close/equal to 1 or -1 is significant.

Correlation analysis data were from 0-20 cm depth, because Fusarium oxysporum was highly isolated (abundant) from this depth (top soil horizon) than $20-50 \mathrm{~cm}$ depth.

$\mathrm{DI}$, disease severity (\%); $\mathrm{pH}$, soil pH; EC, electrical conductivity ( $\mu \mathrm{S} / \mathrm{cm}) ; \mathrm{N}$, nitrogen (\%); $\mathrm{P}$, phosphorus in $\mathrm{mg} / 100 \mathrm{~g}$ of soil; $\mathrm{C}$, organic carbon (\%); $\mathrm{ST}$, soil temperature $\left({ }^{\circ} \mathrm{C}\right) ; \mathrm{AT}$, air temperature $\left({ }^{\circ} \mathrm{C}\right) ; \mathrm{RH}$, relative humidity $(\%)$.

6.7 under $20-50 \mathrm{~cm}$ depth. However, some soil $\mathrm{pH}$ values at the depth of $0-20 \mathrm{~cm}$ were slightly higher than that of $20-50 \mathrm{~cm}$ with the exception of Liwale district (Table 2). The severity at Liwale district (58\%) was also high implying a positive correlation. Soil salt analysis was conducted whereby electro-conductivity was measured and ranged from 2.51 to $16.53 \mu \mathrm{S} / \mathrm{cm}$ across the districts. The analysis of soil mineral nutrients revealed that, the areas experience low amount of mineral nutrients with the exception of organic carbon, which recorded slightly higher percentages for Nachingwea and Masasi (Table 2). Higher soil temperature was recorded compared to air temperature in all the studied districts. The highest soil temperature was $35.6^{\circ} \mathrm{C}$, which was recorded at Mkuranga while the lowest was $28.4^{\circ} \mathrm{C}$ at Tandahimba. The air temperature recorded ranged from $26.6^{\circ} \mathrm{C}$ to $31.4^{\circ} \mathrm{C}$ at Tandahimba and Mkuranga, respectively. Similarly the soil temperature recorded ranged from $28.4^{\circ} \mathrm{C}$ (Tandahimba) to $35.6^{\circ} \mathrm{C}$ (Mkuranga) implying that there is positive correlation

Table 4. Spearman correlation matrix between ecological factors and disease severity

\begin{tabular}{lccccccccc}
\hline & DSV & N & P & C & pH & EC & ST & AT & RH \\
\hline DSV & 1.000 & & & & & & & & \\
N & -0.58 & 1.000 & & & & & & & \\
P & -0.943 & 0.667 & 1.000 & & & & & & \\
C & -0.116 & 0.368 & 0.377 & 1.000 & & & & & \\
pH & 0.600 & -0.464 & -0.543 & 0.377 & 1.000 & & & & \\
EC & 0.714 & -0.174 & -0.600 & 0.464 & 0.829 & 1.000 & & & \\
ST & 0.943 & -0.348 & -0.829 & 0.058 & 0.486 & 0.771 & 1.000 & & \\
AT & 0.812 & 0.000 & -0.667 & 0.176 & 0.464 & 0.783 & 0.899 & 1.000 & \\
RH & 0.771 & -0.058 & -0.657 & 0.319 & 0.714 & 0.943 & 0.829 & 0.928 & 1.000 \\
\hline
\end{tabular}

If $\rho$ value close/equal to 1 or - is significant.

Correlation analysis data were from 0-20 cm depth, because Fusarium oxysporum was highly isolated (abundant) from this depth (top soil horizon) than $20-50 \mathrm{~cm}$ depth.

DSV, disease severity (\%); $\mathrm{N}$, nitrogen (\%); $\mathrm{P}$, phosphorus in $\mathrm{mg} / 100 \mathrm{~g}$ of soil; $\mathrm{C}$, organic carbon (\%); $\mathrm{pH}$, soil pH; $\mathrm{EC}$, electrical conductivity $(\mu \mathrm{S} / \mathrm{cm}) ; \mathrm{ST}$, soil temperature $\left({ }^{\circ} \mathrm{C}\right) ; \mathrm{AT}$, air temperature $\left({ }^{\circ} \mathrm{C}\right) ; \mathrm{RH}$, relative humidity $(\%)$. 


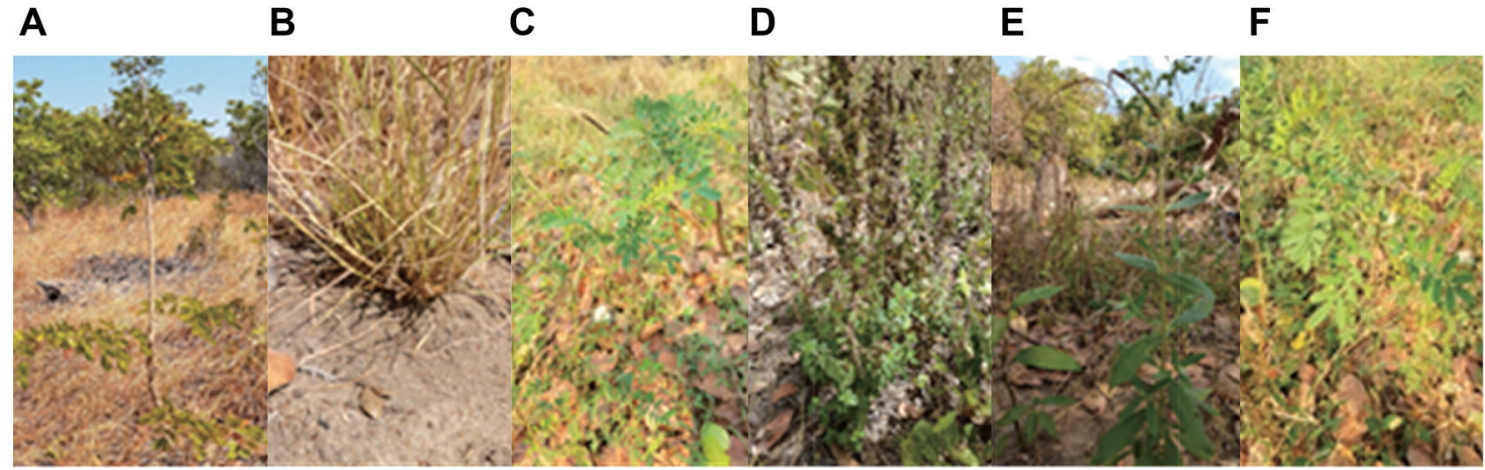

Fig. 5. Common weeds from which roots were sampled for isolation of Fusarium oxysporum. (A) Julbernardia paniculata (Fabaceae). (B) Hyparrhenia rufa (Poaceae). (C) Tephrosia vogelii (Fabaceae). (D) Hyptis suaveolens (Lumiaceae). (E) Trichodesma zeylanicum (Boraginaceae). (F) Tephrosia vogelii (Fabaceae).

between temperatures and the disease across the districts. A similar observation was made for the relative humidity, which was higher (77\% at Masasi) and the lowest relative humidity (59\%) was recorded at Tandahimba.

Host range of Fusarium oxysporum in the infected cashew fields. About six weeds were sampled per site and some of these were sampled in more than one site (Fig. 5A-F). All root samples collected from common weeds under infected cashew trees were free from F. oxysporum infection. The PDA culture indicated no growth of any Fusarium species in terms of cultural morphology.

\section{Discussion}

Isolation and morphological identification of $F$. oxysporum. The culture growth and microscopic characteristics on PDA of root sections from infected cashew were evident of $F$. oxysporum. This implied that leaf (yellow and brown leaves) and root/stem (brown spots) symptoms observed were indicative of cashew Fusarium wilt disease. Similarly Pérez-Vicente et al. (2014), Tibuhwa and Shomari (2016), and Mbasa et al. (2020) described the same morphological features of the causative agent (F. oxysporum) of banana and cashew wilt disease, respectively.

Incidence and severity of Fusarium wilt of cashew. This study revealed variations of incidence and severity of Fusarium wilt disease among the studied locations. Liwale district recorded the highest percentage of disease incidence (35.6\%) compared to other studied districts. Availability of favourable conditions in the area including light soil texture (sandy and sandy loam) which harbor low microbial diversity (Pérez-Vicente et al., 2014; Ploetz 2015), high air and soil temperature of about $31-35^{\circ} \mathrm{C}$ and relative humidity of above $70 \%$ that favor the pathogen sporulation are reported to influence incidence and severity of the cashew wilts disease (Tibuhwa and Shomari, 2016). Variation of disease incidences among the studied districts was also observed. Variation in soil pH and mineral nutrients levels between locations, significantly affects disease incidences (Fang et al., 2012). Similarly, differences in the level of understanding about the disease, soil heterogeneity, inoculum load, edaphic factors (Gupta et al., 2010; Kravchenko et al., 2018), and anthropogenic factors which include human activities (unintentional use of infected farm tools, planting materials, livestock movement on the infected zone) (Devika et al., 2017; Perez-Vicente et al., 2014) cause disease severity variations among locations. The lowest disease severity was recorded in Mkuranga district (12.8\%). This could be due to cultural practices of the disease management that was observed in the studied area. Cashew farmers in Mkuranga district continually prevented further spread of the disease by cutting and burning the infected trees and quarantine of plant materials (seeds, seedlings, and chopping woods) to the safe zones, which prompts the reduction of inoculum load in the infected sites. Similarly, Perez-Vicente et al. (2014) and Orr and Nelson (2018) reported similar findings on Fusarium wilt of banana.

Ecological factors that influence incidence and severity of Fusarium wilt of cashew. The relationship between ecological factors and disease severity of $F$. oxysporum has been 
reported by several studies (Huang et al., 2012; Pérez-Vicente et al., 2014). The current study revealed that soil pH values at both depths influence $F$. oxysporum virulence. Soil pH values below or close to 7 influence the sporulation of the pathogen and leads to high disease severity (Domínguez et al., 2000). Some values at $0-20 \mathrm{~cm}$ depth were slightly higher compared to those of $20-50 \mathrm{~cm}$ with the exception of cashew farms in Liwale and Masasi districts. Soil pH decreases with depth in highly leaching soil (Reeves and Liebig, 2016). High temperature and rainfall favor pathogen development and growth (Tarkalson et al., 2010). Most of the cashew fields across the districts experienced low level of soil mineral nutrients leading to the increase of disease incidence and severity. Soil mineral nutrients among others at optimum or higher levels in soils have been reported to reduce the growth and sporulation of $F$. oxysporum (Domínguez et al., 2000; Orr and Nelson, 2018). Soil and air temperature above $26^{\circ} \mathrm{C}$ was recorded in all of the studied sites. A study by Attri et al. (2018) in Bell paper indicated that sporulation of $F$. oxysporum f. sp. capsici is favored by a temperature range of between $25-30^{\circ} \mathrm{C}$. The association between soil temperature and Fusarium wilt disease severity has been reported in the previous studies; for instance, Fusarium wilts in banana (Devika et al., 2017; Peng et al., 1999) and tomato crops. Most of the studied areas also experienced high relative humidity, which is also one of the factors leading to a disease severity (Peng et al., 1999).

Correlation analysis indicated both positive and negative correlations between edaphic factors and incidence/severity of Fusarium wilt of cashew; similar to previous studies in other crops (Orr and Nelson, 2018; Rousk et al., 2010). The study also depicted strong correlation with disease severity than with disease incidence. This might be attributed to increased disease on or within a single plant (or entity) and is related to a very much more localized dispersal while low correlation of disease incidence might be due to an increased disease resulting from plant to plant (entity-to entity) disease spread and in part is related to the distance from the inoculum source. This study further observed positive correlations between soil pH, soil, and air temperatures, and relative humidity with disease incidence/severity. However, a study by Domínguez et al. (2000) reported soils with pH values close to 7 are not favourable to Fusarium wilt. Similarly, Peng et al. (1999) reported that, $\mathrm{pH}$ values below 6.5, increase severity of Fusarium wilt disease. In another study by Orr and Nelson
(2018), a negative correlation between soil pH and Fusarium wilt disease severity was observed. The negative correlations were observed between mineral nitrogen, phosphorus, and organic carbon with Fusarium disease incidence/severity. Nutrients levels in the soil influence severity of Fusarium wilt on many crops (Gupta et al., 2010; Kravchenko et al., 2018; Perez-Vicente et al., 2014). Mineral nitrogen is one of the nutrients that play a great role on the severity of Fusarium wilt disease (Kravchenko et al., 2018). This study recorded a negative correlation between nitrogen and disease incidence/ severity. When nitrogen is supplied in the form of nitrate, it creates a suppressive environment to Fusarium spp. (Orr and Nelson, 2018; Pérez-Vicente et al., 2014). Similar result was reported in fava bean and banana (Domínguez et al., 2000). The affected cashew fields across the districts recorded low levels of phosphorus, and organic carbon (Table 2). Low levels of phosphorus and organic carbon favor the development and growth of Fusarium pathogen (Domínguez et al., 2000; Ruano-Rosa and Mercado-Blanco, 2015).

Host range of F.oxysporum. The current study focused on the dominant weed hosts, which were collected under the infected cashew fields for isolation of the F. oxysporum. No F. oxysporum was isolated; instead, Aspergillus spp. and Trichoderma spp. were mostly isolated. The isolated two genera are soil-borne fungi. Therefore, the current findings imply that, there might not be F. oxysporum in the weeds due to host specificity and the presence of endophytic fungi that form endophyte. Plant relationship (mutualistic relationship) might be another reason that prevented colonization of the pathogen (Abdel-lateif, 2017). Most members of the kingdom fungi are hosts specific (Groenewald, 2005). However, F. oxysporum pathogen can affect broad range of weed hosts (Hennessy et al., 2005). For instance, F. oxysporum f. sp. cubense was isolated in Commelina diffusa weed as carrier (Pérez-Vicente et al., 2014) and F. oxysporum f. sp. lycopersici was isolated in two hosts; Amaranthus retroflexus and Chenopodium album plants (Fassihiani, 2000).

Conclusion. The results from this study indicated the presence of favorable conditions for the growth and development of Fusarium pathogen which led to high disease incidence and severity. Some soil nutrients for example, mineral nitrogen and phosphorus were recorded very low and low in all studied sites $(<10$ and $0.01-0.15 \mathrm{mg} / 100 \mathrm{~g}$ of soil 
respectively). The low levels of these soil nutrients have been observed to influence the disease severity of the infected cashew fields. However, laboratory results on host range particularly weeds surrounded the affected cashew trees indicated no presence of Fusarium pathogen, suggesting that the pathogen, F. oxysporum are host specific or semi selective.

Thus, management of the disease requires soil amendments, which include nutrients replenishment (rising soil nutrients to optimal levels which creates unfavourable environment for pathogen sporulation) as an essential component in developing appropriate strategies for the control and prevention of the further spread of the disease.

Recommendations. This study recommends holistic approach of the disease management (CFWD). These can include; intercropping cashew with leguminous crops or the application of nitrate-containing fertilizer as the sources of nitrogen and application of phosphorus-containing fertilizer, soil amendments such as shading with the use of cover crops to reduce soil temperature $\left(<30^{\circ} \mathrm{C}\right)$ which reduces pathogen sporulation. Similarly, screening for fungicides and development or evaluation of cashew cultivars resistant or tolerant to disease can be a final resort.

\section{Conflicts of Interest}

No potential conflict of interest relevant to this article was reported.

\section{Acknowledgments}

We acknowledge the Government of Tanzania through the Ministry of Agriculture (Cashew Research Programme) for funding support.

We would also like to acknowledge farmers' maximum cooperation for providing cashew fields to conduct this study. We also wish to thank Laurence Emmanuel for GIS support, Isaya Mwakabaga and Betram Barnabas for their support during field activities. Cordial gratitude and appreciation go to Mr. Charles Kweyunga, Laboratory Technician (Botany Department) at the University of Dar es Salaam for his laboratory technical support. Authors would like to acknowledge the University of Dar es Salaam and TARI Naliendele for providing important facilities for this study.

\section{References}

Abdel-lateif, K. S. 2017. Trichoderma as biological control weapon against soil borne plant pathogens. Afr. J. Biotechnol. 16: 22992306.

Alves-Santos, F. M., Benito, E. P., Eslava, A. P. and Díaz-Mínguez, J. M. 1999. Genetic diversity of Fusarium oxysporum strains from common bean fields in Spain. Appl. Environ. Microbiol. 65: 33353340.

Amata, R. L., Otipa, M. J., Waiganjo, M., Wabule, M.,Thuranira, E. G., Erbaugh, M. et al. 2009. Incidence, prevalence and severity of passion fruit fungal diseases in major production regions of $\mathrm{Ke}-$ nya. J. Appl. Biosci. 20: 1146-1152.

Attri, K., Sharma, M. and Gupta, S. K. 2018. Influence of edaphic factors on Fusarium wilt of bell pepper. Int. J. Bio-resour. Stress Manag. 9: 606-610.

Campbell, C. L. and Neher, D. A. 2016. Estimating disease severity and incidence. In: Epidemiology and Management of Root Diseases, eds. by C. L. Campbell and D. M. Benson, pp. 117-147. Springer, Berlin, Germany.

Devika, B., Fatima, S. and Sonawane, B. N. 2017. Impact of physical factors on growth and sporulation of saprophytic pathogenic fungi. Int. J. Eng. Dev. Res. 5: 1346-1350.

Domínguez, J., Negrín, M. A. and Rodríguez, C. M. 2000. Aggregate water-stability, particle-size and soil solution properties in conducive and suppressive soils to Fusarium wilt of banana from Canary Islands (Spain). Soil Biol. Biochem. 33: 449-455.

Dominic, M. and Makobe, M. 2016. Biological control of cashew powdery mildew using Ampelomyces quisqualis Ces. J. Biol. Control 30: 226-235.

Fang, X., You, M. P. and Barbetti, M. J. 2012. Reduced severity and impact of Fusarium wilt on strawberry by manipulation of soil $\mathrm{pH}$, soil organic amendments and crop rotation. Eur. J. Plant Pathol. 134: 619-629.

Fassihiani, A. 2000. Symptomless carriers of the causal agent of tomato wilt pathogen. J. Agric. Sci. Technol. 2: 27-32.

Food and Agriculture Organization of the United Nations. 1982. Micronutrients and the Nutrient Dtatus of Soils: A Global Study. FAO Soils Bulletin. Food and Agriculture Organization of the United Nations, Rome, Italy. 458 pp.

Food and Agriculture Organization of the United Nations. 2015. World Reference Base for Soil Resources 2014. International Soil Classification System for Naming Soils and Creating Legends for Soil Maps. Food and Agriculture Organization of the United Nations, Rome, Italy. 192 pp.

Gheorghe, B. A., Stelica, C., Relu, Z. C. and Maria, O. 2015. The biological growth parameters of the Fusarium oxysporum f. sp. glycines fungus. Rom. Biotechnol. Lett. 20:10921-10928.

Groenewald, S. 2005. Biology, pathogenicity and diversity of Fusarium oxysporum f. sp. cubense. M.S. thesis. University of Pretoria, Pretoria, South Africa. 158 pp. 
Gupta, V. K., Misra, A. K. and Gaur, R. K. 2010. Growth characteristics of fusarium spp. causing wilt disease in Psidium guajava $L$. in india. J. Plant Prot. Res. 50: 452-462.

Hennessy, C., Walduck, G., Daly, A. and Padovan, A. 2005. Weed hosts of Fusarium oxysporum f. sp. cubense tropical race 4 in northern Australia. Aust. Plant Pathol. 34: 115-117.

Huang, Y. H., Wang, R. C., Li, C. H., Zuo, C. W., Wei, Y. R., Zhang, L. et al. 2012. Control of Fusarium wilt in banana with Chinese leek. Eur. J. Plant Pathol 134: 87-95.

Jiménez-Díaz, R. M., Castillo, P., Jiménez-Gasco, M., Landa, B. B. and Navas-Cortés, J. A. 2015. Fusarium wilt of chickpeas: biology, ecology and management. Crop Prot. 73: 16-27.

Kravchenko, Y., Kursitys, I. and Kravchenko, D. 2018. Architecture and method of integrating information and knowledge on the basis of the ontological structure. In: Advances in Artificial Systems for Medicine and Education: Advances in Intelligent Systems and Computing, Vol. 658, eds. by Z. Hu, S. Petoukhov and M. He, pp. 93-103. Springer, Cham, Switzerland.

Lichtenzveig, J., Anderson, J., Thomas, G., Oliver, R. and Singh, K. 2006. Inoculation and growth with soil borne pathogenic fungi. In: The Medicago Truncatula Handbook, eds. by M. Mathesius, E. P. Journet and L. W. Sumner, pp. 1-10. The Samuel Roberts Noble Foundation, Ardmore, OK, USA.

Lima, J. S., Martins, M. V. V. and Cardoso, J. E. 2019. Powdery mildew damage to the production of BRS 189 cashew plants. Rev. Ceres Vicosa 66: 132-141.

Madeni, J. P. N. 2016. Genotype $\times$ environment interaction on perfomance of selected cashew (Anacardium occidentale L.) hybrids in Tanzania. Ph.D. dissertation. Sokoine University of Agriculture, Morogoro, Tanzania. $98 \mathrm{pp}$.

Matić, S., Gilardi, G., Gullino, M. L. and Garibaldi, A. 2018. Evidence for an expanded host range of Fusarium oxysporum f. sp. chrysanthemi. J. Plant Pathol. 100: 97-104.

Mbasa, W. V., Nene, W. A., Kapinga, F. A., Lilai, S. A. and Tibuhwa, D. D. 2020. Characterization and chemical management of cashew Fusarium wilt disease caused by Fusarium oxysporum in Tanzania. Crop Prot. 139: 105379.

Molina, A. B., Williams, R. C., Hermanto, C., Suwanda, Komolong, B. and Kokoa, P. 2010. Mitigating the Threat of Banana Fusarium Wilt: Understanding the Agroecological Distribution of Pathogenic Forms and Developing Disease Management Strategies. Final Report HORT/2005/136. Australian Centre for International Agricultural Research, Canberra, Australia. 76 pp.

Msoka, R., Kassim, N., Makule, E. and Masawe, P. 2017. Physio-chemical properties of five cashew apple (Anacardium occidentale L.) varieties grown in different regions of Tanzania. Int. J. Biosci. 11: 386-395.

Nene, W., Rwegasira, G. M. and Mwatawala, M. 2017. Optimizing a method for loacting queen nests of the weaver ant Oecophylla longinoda Latreille (Hymenoptera: Formicidae) in cashew, Anacardium occidentale L. plantations in Tanzania. Crop Prot. 102: 81-87.

Nene, W. A., Shomari, S. H. and Assenga B. B. 2017. The efficacy of botanical pesticides for managing powdery mildew, Oidium anacardii Noack disease in cashew, Anacardium occidentale L. plantations in Tanzania. Res. J. Agric. For. Sci. 5: 1-6.

Orr, R. and Nelson, P. N. 2018. Impacts of soil abiotic attributes on Fusarium wilt, focusing on bananas. Appl. Soil Ecol. 132: 20-33.

Patra, S., Biswas, M. K. and Mahato, A. 2017. Prevalence of Fusarium wilt of chickpea in the agro-ecological condition of undulating red and lateritic zone of West Bengal, India. Int. J. Curr. Microbiol. Appl. Sci. 6: 2456-2462.

Peng, H. X., Sivasithamparam, K. and Turner, D. W. 1999. Chlamydospore germination and Fusarium wilt of banana plantlets in suppressive and conducive soils are affected by physical and chemical factors. Soil Biol. Biochem. 31: 1363-1374.

Pérez-Vicente, L., Dita, M. A. and de la Parte, E. M. 2014. Technical Manual Prevention and Diagnostic of Fusarium Wilt (Panama Disease) of Banana Caused by Fusarium oxysporum f. sp. cubense Tropical Race 4. Food and Agriculture Organization of the United Nations, Rome, Italy. 75 pp.

Ploetz, R. C. 2015. Fusarium wilt of banana. Phytopathology 105: 1512-1521.

Reeves, J. L. and Liebig, M. A. 2016. Depth matters: soil pH and dilution effects in the Northern Great Plains. Soil Sci. Soc. Am. J. 80: 1424-1427.

Rico, R., Bulló, M. and Salas-Salvadó, J. 2015. Nutritional composition of raw fresh cashew (Anacardium occidentale L.) kernels from different origin. Food Sci. Nutr. 4: 329-338.

Rousk, J., Bååth, E., Brookes, P. C., Lauber, C. L., Lozupone, C., Caporaso, J. G. et al. 2010. Soil bacterial and fungal communities across a pH gradient in an arable soil. ISME J. 4: 1340-1351.

Rowland, A. P. 1983. An automated method for the determination of ammonium in ecological materials. Commun. Soil Sci. Plant Anal. 14:49-63.

Ruano-Rosa, D. and Mercado-Blanco, J. 2015. Combining biocontrol agents and organics amendments to manage soil-borne phytopathogens. In: Organic Amendments and Soil Suppressiveness in Plant Disease Management. Soil Biology, Vol. 46, eds. by M. K. Meghvansi and A. Varma, pp. 457-478. Springer, Cham, Switzerland.

Sijaona, M. E. R., Reeder, R. H. and Waller, J. M. 2006. Cashew leaf and nut blight: a new disease of cashew in Tanzania caused by Cryptosporiosis spp. Plant Pathol. 55: 576.

Tarkalson, D., Shapiro, C. A. and Petersen, J. L. 2010. Use of fly ash as a liming material of corn and soybean production on an acidic sandy soil. Crop Manag. 9: 1-12.

Tibuhwa, D. D. and Shomari, S. 2016. Fusarium wilt disease: an emerging threat to cashew nut crop production in Tanzania. Asian J. Plant Pathol. 10: 36-48.

Walkley, A. 1947. A critical examination of a rapid method for determination of organic carbon in soils: effect of variations in digestion conditions and of inorganic soil constituents. Soil Sci. 63: 251-264. 